\title{
Tumor Infiltrating Lymphocyte
}

National Cancer Institute

\section{Source}

National Cancer Institute. Tumor Infiltrating Lymphocyte. NCI Thesaurus. Code C12546.

Lymphocytes that show specificity for autologous tumor cells and can infiltrate a tumor. 